\title{
Article \\ The Long-Term Care with Focus on an Integrative Care Model in the Slovak Republic: A Pilot Study
}

\author{
Anna Vallušová ${ }^{1}$, Andrea Seberíni ${ }^{1}$, Alena Kašćáková ${ }^{2}$, Mária Horehájová ${ }^{1, *}$ and Miroslava Tokovska ${ }^{3}$ (i) \\ 1 Department of Economics, Matej Bel University, Tajovského 10, 97590 Banská Bystrica, Slovakia; \\ anna.vallusova@umb.sk (A.V.); andrea.seberini@umb.sk (A.S.) \\ 2 Department of Quantitative Methods and Information Systems, Matej Bel University, Tajovského 10, \\ 97590 Banská Bystrica, Slovakia; alena.kascakova@umb.sk \\ 3 Institute for Health and Training, School of Health Sciences, Kristiania University College, 0152 Oslo, Norway; \\ Miroslava.Tokovska@kristiania.no \\ * Correspondence: maria.horehajova@umb.sk
}

check for

updates

Citation: Vallušová, Anna, Andrea Seberíni, Alena Kaščáková, Mária Horehájová, and Miroslava Tokovska. 2022. The Long-Term Care with Focus on an Integrative Care Model in the Slovak Republic: A Pilot Study. Social Sciences 11: 38. https:// doi.org/10.3390/socsci11020038 Academic Editor: Dennis P. Culhane

Received: 14 November 2021

Accepted: 20 January 2022

Published: 24 January 2022

Publisher's Note: MDPI stays neutral with regard to jurisdictional claims in published maps and institutional affiliations.

Copyright: (c) 2022 by the authors. Licensee MDPI, Basel, Switzerland. This article is an open access article distributed under the terms and conditions of the Creative Commons Attribution (CC BY) license (https:// creativecommons.org/licenses/by/ $4.0 /)$.

\begin{abstract}
An integrative care model is a challenge and the future of social and healthcare systems globally in establishing interdisciplinary cooperation. The integrative care model responds to the needs of patients suffering from various diseases as well as their families. Planning and policy making should involve professionals in both the medical and social care disciplines; additionally, the management and administrators of social and healthcare services, at both the national and community levels, are crucial in integrating health services. This article aims to present and describe the selection methods of functional groupings of municipalities as appropriate locations for implementing care practices for elderly, in this case an integrative social and health services model. The study employed an exploratory mixed methods design. The proposed methodology of the selection of the functional groupings of municipalities has a mixed-methodological character, consisting of quantitative as well as qualitative methods. Our research focused on quantitative data processing using two approaches: the multicriteria evaluation method to create a composite index and the ArcGIS system to express the geographical distribution of the value of the composite index. The qualitative document study was applied to analyses of community-based plans for health and social services. The methodology also includes an evaluation of municipalities, which was not the subject of our paper. Furthermore, the article suggests the need to consider other factors in connection with the methodology of the selection of functional groupings and explains some of its limitations in the discussion.
\end{abstract}

Keywords: long-term care; integrative care model; elderly; methods; functional grouping of municipalities; Slovakia

\section{Introduction}

Long-term care (LTC) includes the broad array of services provided to disabled persons-particularly the elderly because of chronic illness or disability-at home, in nursing homes, and in assisted-living facilities. These services are provided to improve personal functioning and quality of life (The Organisation for Economic Co-Operation and Development 2011; Stallard 2017; Freeman et al. 2017).

The integration of social and healthcare is a complex process that is dependent on a plethora of factors (Struijs et al. 2015; World Health Organisation 2015; Wodchis et al. 2018). Research to date provides some evidence that providing integrative care can lead to positive patient outcomes (Baxter et al. 2018; Liljas et al. 2019; de Bruin et al. 2020; Porteus 2011). Integrated care is a strategy for improving patient care, specifically through better coordination (Shaw et al. 2011; Chen et al. 2020; Craftman et al. 2018; Mauriat et al. 2009). The integrated care model responds to the needs of people suffering from rare diseases as well as their families (Czerska and Skweres-Kuchta 2021). The World Health Organization (World Health Organisation 2016) defines integrated health services delivery 
as "an approach to strengthen people-centred health systems through the promotion of the comprehensive delivery of quality services across the life-course, designed according to the multidimensional needs of the population and the individual, and delivered by a coordinated multidisciplinary team of providers working across settings and levels of care".

The integration of social and healthcare services in Slovakia has been continually discussed over the past 20 years. The numerous intentions for preparing a legal framework for long-term care were rejected due to the lack of political will and lack of cooperation between stakeholders; however, there have been some small adjustments made in recent years. The integrative care model is widely recognised as an approach which helps address challenges that are typical for Slovakia's social and healthcare system: fragmentation, overspecialization, discontinuity of care, the dominance of the institutional model of care provision, focus on the treatment of acute conditions rather than on prevention, etc. It is globally acknowledged that improving the experience of people in need of care can be achieved by making the system more efficient and less costly-by shifting from acute to preventive care-and helping people retain their self-sufficiency. To improve the quality of elderly care and ensure that it matches the needs of the population-while also overcoming the challenges of the fragmentation of the system and avoiding huge opportunity costsSlovakia should move towards integration of care.

Long-term care of the elderly in the Slovak Republic is a fragmented system. Social and healthcare services remain two separate systems with minimal coordination and interconnection. Each system is governed by its own legislation and standards. This results in a very complicated system regulated by more than three different legal acts-Act no. 448/2008 on Social Services, Act no. 576/2004 Health Care, and Act no. 447/2008 on Financial Benefits to Compensate for Severe Disabilities. Care for the elderly is mostly provided within social care facilities, including outreach, outpatient, and (mainly) residential. The system also relies on informal care, which is supported by allowances for caregivers-usually the next of kin of the elderly in need. The current legislation puts a greater share of social care responsibilities on municipalities, although they are not well positioned to fulfill this responsibility. There are nearly 3000 municipalities in Slovakia, most of them inhabited by several hundred people (65.96\% of municipalities have less than 1000 inhabitants) (Statistical Office of the Slovak Republic 2020). They lack the trained personnel, equipment, infrastructure, and financial resources to provide appropriate elderly care (Ministry of Social Affairs 2020). The provision of social care services is decentralised towards self-governing regions and municipalities. Public providers are established and financed by the municipalities or self-governing regions. Non-public providers are established by NGOs or churches, and they are financed partially from the state budget and municipal or self-governing regional budgets. There are no social care services fully provided by the public sector. The main difference between providers depends on their financing and access to public funds.

The consequence of this situation is a complicated system of funding of social services and an unequal spatial distribution of people in need of social care. Formal legislation supports a subsidiarity principle, which means that the most support and care should be provided in the natural home environment of users. If care and support cannot be provided in the home environment, the users should go to institutional care. However, under the current system, the social care services provided in an institutional form are better funded than the community-based services. Municipalities do not have sufficient resources for providing care at the community level, so they resort to recommending citizens to use a regional institutional social care infrastructure, even if they do not need such a level of care and even if it forces them to leave their communities. Most capacity for care provision is concentrated in the institutional care facilities of self-governing regions and private providers. Moreover, most of the social care service providers who deliver community-based services are private providers. Long-term care (LTC) in Slovakia suffers from underfunding, which is the reason for the insufficient availability of these services. While LTC is supposed to combine healthcare and social services, there is no systemic 
service coordination or even integration between these two. Home-based health care is provided mainly by visiting nurses, home physician visits, and assistance provided by mobile hospices. Due to the aforementioned situation in Slovakia, we consider it important to set the appropriate methodological solution for long-term care with focus on an integrative care model.

The aim of the article is to describe how, and according to which criteria, it is possible to create a functional groups of municipalities in order to provide integrated social and health services for elderly from a community-based social service centre (CSSC). Thus, we will describe the selection methods of functional groupings to determine appropriate locations and what needs to be considered in implementing care practices, in this case an integrative care model. In the long run, there is a vision that a network of CSSCs will cover the whole territory of Slovakia. In this phase, the resources are restricted to a pilot operation of three CSSCs. Therefore, in this article, we describe the approach of the Banská Bystrica self-governing region to select and form the functional grouping of municipalities that will run the pilot operation. The selection process itself has several stages, as explained below. The paper is focused on the first stage, in which we have used data describing the economic, social, and demographic situation of the municipalities to find regions with the highest urgency of intervention. We develop a method of multicriterial evaluation of given indicators and demonstrate its usage on the example of municipalities of BBSG region. We used data from publicly available databases, namely: the database on economy of municipalities compiled by Goliáš et al. (2021), reports of the Social Insurance Company, and census data compiled by the Slovak Statistical office. As to the ethical consideration, we used publicly available aggregated data, which have been properly anonymised.

\section{Materials and Methods}

This study adopts a mixed methods approach through quantitative and qualitative research (Creswell and Clark 2017). In accordance with this design, in the first phase we used multicriteria evaluation of collected data together with ArcGIS system to express the geographical distribution of the value of the composite index. This methodology was completed with the qualitative document analysis of community-based plans for health and social services. It is important to note that document analysis is a process that involves skimming (superficial examination), reading (thorough examination), and interpreting content to provide answers to the research questions (Parveen and Showkat 2017).

Since 2020, we have been implementing a pilot project in Slovakia, with a focus on creating a functioning pilot model of community-based social service centres (CSSCs) for the elderly. The centres will serve as a platform for integrating the social and healthcare services of various providers in two ways: geographically and structurally. Geographically, the centres will horizontally connect several local municipalities. Through the centres, associated municipalities will provide social and healthcare services for the elderly in an area larger than a single municipality (as there are many municipalities with fewer than 1000 inhabitants in the Slovak Republic). Centres will concentrate social care services provided by municipalities. This will create conditions for the provision of social care services that do not currently exist in the region or are insufficient to meet the increasing needs of an aging population, and for increasing the quality and efficiency of services already provided. Structurally, they will form a platform enabling the vertical interconnection of local, regional, and national levels of social and healthcare services for the elderly in Slovakia.

We assume that by interconnecting municipalities and providers, it is possible to achieve a more coordinated and targeted system of flexible and sustainable services, covering preventive activities, outpatient, and residential social care services, including long-term care. The main idea with this pilot project is to bring social care services directly to the recipient in their home environment, whenever their health. The proposed activity covers the design and pilot testing of a CCSC model in three small regions, with the possibility of applying the created model to other territories of Slovakia. The results of the pilot test will 
be analysed and evaluated within the working group with the participation of the Ministry of Labour, Social Affairs and Family as a basis for setting the criteria for further use of EU funds, legislative processes, and long-term care reforms in the Slovak Republic.

Target groups are defined as follows:

- Senior citizens (CSSCs recipients)

- Family members of a senior citizen who are provided with a service through CSSCs

- Municipalities

- Banská Bystrica self-governing region (BBSGR)

CSSCs helps seniors to select and ensure the right "mix" of social services that meets the individual's requirements-the preference of community social services versus institutional services. The elderly will be provided with a nursing service, a relieving service in the home environment, and a transport service for seniors with limited mobility and immobile citizens who are affected by transport or who do not have the opportunity to travel by car, e.g., to medical facilities for examination, collection, or control, to authorities, etc. The advantage of provided services is that the senior will be provided with a service according to their preferences and needs in the municipality and will not have to travel for services. The current capacities of these services in Slovakia are undersized. CSSCs activity at the local level will expand and fill the gap (lack of services) to reflect the current needs of seniors and saturate them directly in the home environment. CSSCs will provide emergency care service, namely rental of SOS monitoring bracelets. Seniors will be sure that they can call for help when they need it, increasing the awareness of seniors about the possibilities of providing long-term care services.

An efficient and affordable service system will enable family members of working age who care for a close senior to return to the labour market.

The existing and functioning CSSCs of the cooperating municipalities that coordinate the provision of social services will increase the number of employees and workers in the community employed in CSSC - model pilot scheme. Creation of a knowledge database with a wide range of methodological materials, guidelines, model and recommended procedures, and catalogues of good practice from abroad, which can serve as inspiration and background for municipalities from other regions of Slovakia.

The Banská Bystrica self-governing region (BBSGR) acquires an elaborated and tested innovative approach to long-term care provision; model of community centres of social services. Gained experience and examples of good practice supported by analyses will serve to expand the activities in the region and also to reform efforts at national level. A long-term care model for the elderly will be set up to take into account local needsstrengthening the responsibility and participation of local capacities in solving the problems of the elderly.

This study presents and describes the method based on the above characteristics and objectives of functional grouping of municipalities (FG) (MH, AV, AK, AS). The Functional Group of Municipalities (FG) is a group of municipalities that are horizontally connected to the Center for Integrated Social and Health Care, in order to provide social and healthcare services for the elderly in individual municipalities in the required quantity and quality, with emphasis on the field form of their provision.

The methods of assessing the potential location of a facility are well developed in various areas of the public and private spheres, from the optimal allocation of warehouses and local branches to serve the customer to the design of public services such as the police, fire stations and health care. Owen and Daskin (1998) distinguish two basic approaches to the problem of location-static (deterministic) and dynamic (stochastic). The former evaluates chosen criteria based on an objective (or multiple objectives) in a given point in time. On the other hand, the dynamic approach accounts for the effect of uncertainty on planning decisions (Cardoso et al. 2015). To choose an appropriate method of selecting location, it is necessary to decide on the criteria according to which the model will be built. Cinnamon et al. (2009) assess the urgency of need for additional medical and social care based on the size of the population living in a certain community, their vulnerability (i.e., 
the number of inhabitants above 65 years) and isolation of the community (i.e., driving time to the closest centre). Cardoso et al. (2015) pick minimalization of delivery cost as the primary criterion to design the optimal network of health care centres providing long-term care; however, they stress the necessity of taking equity into account. In their understanding, equity consists of several dimensions, namely equity of access (traveling time does not exceed a certain threshold), equity of utilization (there are no significant differences in unmet demand among communities), socioeconomic equity (unmet demand does not vary based on socioeconomic status), and geographical equity (there is certain level of services provision in each region).

The process of FG selection is divided into two stages:

- In the first stage, a grouping of municipalities is created on the basis of quantitative indicators that reflect the economic, demographic, social and geographical characteristics of municipalities. Based on the values of these indicators, it is possible to create a composite index reporting the ranking of municipalities according to their socioeconomic and demographic level.

- The second stage of the FG selection methodology represents a qualitative evaluation of municipalities, which is based mainly on information concerning conditions and forms of cooperation that already exist and, especially, a willingness to cooperate with other municipalities to create a functional system of social and healthcare services for the elderly. Part of this stage is also the selection of one of the municipalities, which will be the seat of the CSSCs.

The use of economic indicators in the selection of FG presupposes knowledge and consideration of the economic situation of individual municipalities. If the economic situation of the municipality is not good, then its possibilities of financing and providing social care services for the elderly, in accordance with Act 448/2008 Coll. (§ 8) on social care services, are limited. For such municipalities, cooperation within the FG appears to be a possible solution to fulfilling the statutory obligation.

To evaluate the economic situation and the management of municipalities, we propose using the aggregated indicator of the financial health of the municipality (E1) (Goliáš et al. 2021). This indicator is created on the basis of five indicators that characterise the municipality's financial management: total debt, debt service, current account balance, overdue liabilities, and liabilities at least 60 days overdue. The aforementioned authors used data for four consecutive years to express the score of each mentioned component. The total score of the financial health of the municipality is calculated as a weighted average of the scores from each of the components (see the calculation methodology). The resulting aggregate indicator of the financial health of the municipality is a number between 0 to 6 ; the higher this number, the better the management of the municipality.

The aforementioned economic indicator of the financial health of the municipality is supplemented by the indicator concerning the number of unemployed resp. number of jobseekers (E2). This indicator expresses the share of the number of inhabitants of the municipality applying for employment from the total number of economically active inhabitants aged from 15 to 64 in the municipality.

An important area in assessing the need to provide social and healthcare services for elderly in individual municipalities is their demographic situation. In order to create FG, three demographic indicators monitored at the municipal level were selected.

- The first indicator is the old age dependency ratio (D1), which is defined as the ratio of the population $65+$ to the number of inhabitants in the age group 15 to 64 years. This indicator, otherwise called 'the index of economic dependence of the elderly', also has an economic dimension in that it indicates how many elderly are living in a given municipality per 100 economically active inhabitants.

- Given that the need to provide social care services grows with age, the second indicator of demographic development is the share of the oldest population (D2) expressed as the ratio of the population aged $80+$ to the total population of the municipality. Both of these indicators (D1, D2) at the municipal level correspond to the defined assumption 
that the higher their values, the greater the need to provide social care services and, thus, the involvement of the municipality in the FG.

- The third indicator, the gross migration rate (D3), reflects the demographic situation in the municipality. This indicator is calculated as the migration balance (the difference between the number of immigrants and emigrants) in relation to the total population in the municipality. Negative values of the migration balance signal a higher intensity of population eviction, which is most often carried out in the age groups of the economically active population-common motives for moving include work or social reasons, such as following a partner. The oldest population, thus, loses the possibility of 'assistance being provided' from the environment of their immediate family.

An important part of assessing the urgency of the need for social care services for the elderly in individual municipalities is their current situation, both in terms of need and the existing structure of services provided. The component reflecting the social area of the model of integrated social and healthcare services includes the need for services, availability and integration of social and healthcare services in the target area. This indicator is created based on five indicators, which characterise:

- the number of people waiting for residential social care service in a facility for the elderly (S1);

- $\quad$ the number of recipients of care allowance for persons aged 65+ (S2);

- the number of people with disabilities $65+$ (S3);

- the number of recipients of cash allowances for compensatory aids aged 65+ (S4); and

- the number of carers (S5).

All the above indicators are recalculated in percentage terms as a share of the total population of the municipality aged 65+; the last of the indicators is recalculated to the number of inhabitants in the municipality. People with disabilities form a significant group of recipients of social care services. Therefore, the selected indicators include the number of severely disabled person aged 65 and over (S3) and the number of severely disabled beneficiaries aged 65 and over (S4). Legislative measures for natural persons with severe disabilities in the Slovak Republic are regulated by Act 447/2008 Coll. on Cash Benefits for Compensation of Severe Disability and via the amendments of other legislative acts.

Financial contributions for compensation may be provided to a natural person with a severe disability, which is considered to be a person whose degree of functional impairment is at least $50 \%$. For this target group, long-term care to varying degrees is necessary throughout their life, requiring a flexible monitoring of the needs of the person as they get older and their health status changes. The indicator on the number of recipients of the care allowance at the age of 65+ (S2) reflects the long-term care provided to the elderly at home. Care for elderly in the household is supported in the form of a care allowance (Act $447 / 2008$ Coll.). Persons with a certain level of dependence on the assistance of another person in self-service V and VI are entitled to the allowance. It is this form of support that takes into account the principle of providing services in the natural environment of the elderly. The availability of social care services is limited mainly by the capacity of the facilities that provide them. The aging of the population is also directly proportional to the growth in the number waiting for the provision of social care services (S1) in social care facilities for the elderly. This factor is likely to be problematic in the future, and, therefore, it is important to support the elderly staying in their home environment for as long as possible, if their health allows it.

The second stage of the selection of municipalities, as we mentioned already, represents a qualitative evaluation of the possibilities of involving the municipality in the FG. This stage is based on information regarding the possibilities, conditions and especially the willingness of the local government to involve the municipality in the FG, and thus participate in the effective functioning of the CSSCs. At the beginning of this stage, it is important to provide municipalities with as detailed information as possible on how CSSCs work, i.e., on their tasks, objectives, and operating conditions, including financial costs. In addition to the activities and mission of the CSSCs, municipalities must also be informed 
about their own position and tasks; furthermore, they should be made aware of the benefits that they could gain from cooperation with other municipalities and CSSCs.

Subsequently, a questionnaire survey is useful to obtain feedback from municipalities, especially the attitude of the mayors or deputies of the municipality, about its involvement in the FG. In addition to the quantitative analysis, the results of the questionnaire survey form a complementary part of the whole process of selecting FG. As mentioned in the introduction, the creation of FG should develop the preconditions for a coordinated, flexible, and sustainable system of providing social care services for the elderly. The evaluation of the questionnaire will provide relevant information for the development of a suitable strategy for communication with the mayors. Their willingness to cooperate and actively participate in the activities of the CSSCs is a prerequisite for the CSSCs to fulfill their function. The last step is to select the municipality in which the CSSCs will be based.

In addition to the above-mentioned questionnaires, joint meetings of the mayors, and their mutual intensive communication, the aspect of the distance of municipalities from the said centre is important for the choice of the CSSCs' seat. In this phase, it is again possible to use GIS with the display of roads and data on the distances of individual municipalities from the CSSCs' headquarters.

\section{Results}

Selected indicators consist of three naturally forming domains-economic (E1, E2), demographic (D1, D2, D3) and social (S1, S2, S3, S4, S5) - describing the situation of the municipalities in the three areas (Table 1). In order to use the indicators when selecting FG, each value of the indicator is transformed into a value that corresponds to the selected methodology of data processing, where individual indicators are expressed in percentages and the logic of their evaluation is defined by the relationship: the higher the percentage, the greater the need for the involvement of the municipality in FG.

Table 1. Descriptive measures of selected indicators in all domains.

\begin{tabular}{|c|c|c|c|c|c|c|c|c|c|c|}
\hline & E1 & E2 & S1 & $\mathrm{S} 2$ & S3 & $\mathrm{S} 4$ & S5 & D1 & D2 & D3 \\
\hline Minimum & 0 & 0 & 0 & 0 & 0 & 0 & 0 & 3.704 & 0 & 0 \\
\hline Maximum & 53.333 & 54.381 & 9.091 & 31.287 & 138.499 & 70.078 & 7.661 & 114.634 & 26.374 & 100 \\
\hline Average & 13.906 & 12.068 & 0.433 & 5.18 & 24.849 & 10.925 & 1.342 & 26.642 & 4.12 & 52.767 \\
\hline Standard deviation & 8.031 & 8.293 & 1.044 & 4.794 & 13.736 & 8.165 & 0.94 & 8.935 & 2.258 & 21.888 \\
\hline Number of municipalities & 515 & 516 & 516 & 516 & 516 & 516 & 516 & 516 & 516 & 516 \\
\hline
\end{tabular}

After aggregation, the selected indicators allow one domain indicator to characterise the level in the relevant area:

- economic-EI;

- demographic-DI;

- $\quad$ social-SI, separately and subsequently to organise municipalities according to the level based on the value of indicators.

Since the aim of the project at this stage is to select municipalities to build a centre of social care services for the elderly, taking into account the situation of the municipality in all three areas simultaneously, a composite indicator (aggregate index) AI was created, which takes into consideration the economic situation, demographic situation, and level of need for social care assistance. From a statistical point of view, diagnostic variables are required to meet the following conditions to create an aggregate index: a low degree of correlation between variables and a high degree of correlation with other variables that do not directly enter the aggregate index. They are not involved in generating the synthetic variable directly, but through diagnostic variables with which they are mutually correlated (Labudová 2020). The correlation between the indicators in the economic and demographic area was very low (Pearson's correlation coefficient $R<|0.18|$ ), thus fulfilling the condition of creating an aggregate index (Table 2). We solved the problem of high dependence of 
social indicators for the creation of an aggregated index in two ways. The first solution was the selection of indicators S1 and S4, which show a low correlation $(R=-0.17)$ and a high correlation of indicator S4 with indicators $S 2, S 3$, and S5 $(R=0.66,0.85$, and 0.51 , respectively).

Table 2. Paired correlations between values of social indicators S1-S5.

\begin{tabular}{|c|c|c|c|c|c|c|}
\hline & & S1 & S2 & S3 & S4 & S5 \\
\hline \multirow{4}{*}{ S1 } & Pearson Correlation & 1 & $-0.130^{* *}$ & $-0.162^{* *}$ & $-0.170^{* *}$ & -0.111 * \\
\hline & Sig.(2-taled) & & 0.003 & 0.000 & 0.000 & 0.011 \\
\hline & $\mathrm{N}$ & 516 & 516 & 516 & 516 & 516 \\
\hline & Pearson Correlation & $-0.130^{* *}$ & 1 & $0.598 * *$ & $0.662 * *$ & $0.768 * *$ \\
\hline \multirow[t]{3}{*}{ S2 } & Sig.(2-taled) & 0.003 & & 0.000 & 0.000 & 0.000 \\
\hline & $\mathrm{N}$ & 516 & 516 & 516 & 516 & 516 \\
\hline & Pearson Correlation & $-0.162 * *$ & $0.598 * *$ & 1 & $0.847 * *$ & $0.404 * *$ \\
\hline \multirow[t]{3}{*}{ S3 } & Sig.(2-taled) & 0.000 & 0.000 & & 0.000 & 0.000 \\
\hline & $\mathrm{N}$ & 516 & 516 & 516 & 516 & 516 \\
\hline & Pearson Correlation & $-0.170 * *$ & $0.662 * *$ & $0.847^{* *}$ & 1 & $0.514 * *$ \\
\hline \multirow[t]{3}{*}{ S4 } & Sig.(2-taled) & 0.000 & 0.000 & 0.000 & & 0.000 \\
\hline & $\mathrm{N}$ & 516 & 516 & 516 & 516 & 516 \\
\hline & Pearson Correlation & $-0.111 *$ & $0.768^{* *}$ & $0.404^{* *}$ & $0.514^{* *}$ & 1 \\
\hline \multirow{2}{*}{ S5 } & Sig.(2-taled) & 0.011 & 0.000 & 0.000 & 0.000 & \\
\hline & $\mathrm{N}$ & 516 & 516 & 516 & 516 & 516 \\
\hline
\end{tabular}

* Correlation is significant at the 0.01 level (2-taled). ${ }^{* *}$ Correlation is significant at the 0.05 level (2-taled).

The second solution was to use factor analysis to create weights of all used social indicators (Nicoletti et al. 2000). Both procedures for the identification of the appropriate social indicators for the construction of composite index gave very similar results. In the group of municipalities with the worst situation in the monitored areas, $88 \%$ were equally identified by the first and second procedures.

The chosen methodology aggregates indicators in three areas into a summary index, according to the following four steps:

1. All indicators are recalculated in the same direction, which means that the higher the value, the higher the need for the municipality to participate in the cooperation of municipalities in terms of providing social care services and, thus, the establishment and functioning of CSSCs.

2. As the individual indicators must have the same unit of measurement (The Organisation for Economic Co-Operation and Development 2008), each of the indicators is expressed as a percentage, with a minimum value of 0 and a maximum value of 100 .

3. The arithmetic mean of the indicators is calculated for each domain. These results then provide three domain-specific indices: the economic index EI, the demographic index DI, and the social index SI.

4. The total composite AI indicator is calculated as the weighted arithmetic mean of indices specific to each domain, while the choice of domain index weights followed the goal of constructing an aggregate index-the selection of municipalities with an unfavorable socioeconomic situation for CSSCs. It is assumed that each of the domains has its own irreplaceable influence on the characteristics of the overall need to establish a centre, but its mission is to focus primarily on the provision of social care services. Therefore, the economic and demographic areas were assigned weights of $25 \%$ and the social area (indicators in the social domain) weights of $50 \%$.

When selecting municipalities for a functional grouping with the aim of joint action and cooperation in the provision of social care services for the elderly, their distance from each other is an important factor determining the grouping of municipalities. For this reason, the FG selection methodology uses the GIS geographic information system.

The ArcGIS system was used to express the geographical distribution of the value of the AI index, in which the database of municipalities of the Banská Bystrica region 
(BBSK) was connected to the created database. For greater clarity, the municipalities were divided into four equal groups based on the value of the AI indicator, which corresponded to the quartiles of the distribution of this indicator. Figure 1 illustrates the geographical distribution of these groups of municipalities within the BBSK districts.

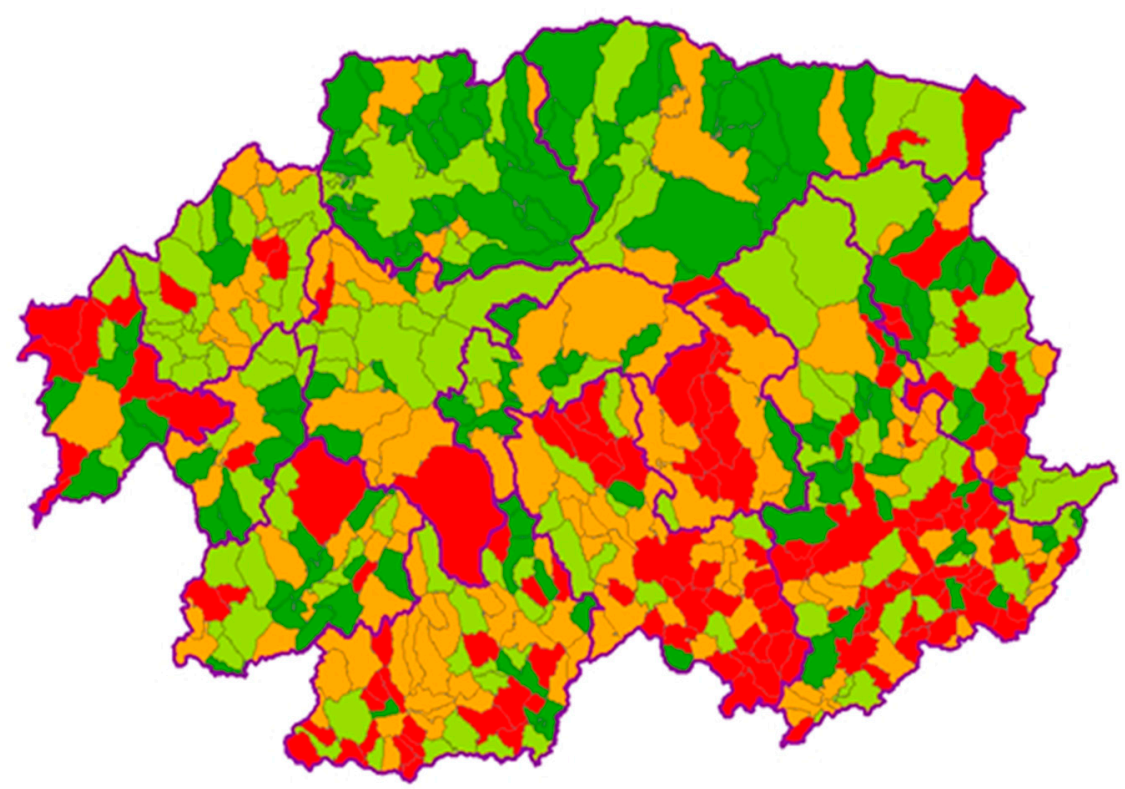

Figure 1. Geographical distribution of municipalities according to the AI index.

\section{Discussion}

The presented approach to the methodology of selecting the location of CSSCs has the following features:

- $\quad$ prioritise equalizing unsatisfied demand;

- target the municipalities with the lowest capacity to address the needs of its citizens, while taking into account the vulnerability of the community;

- $\quad$ simple to use and undemanding for software;

- based on publicly available data;

- static.

All the features are the results of methodological decision, which will be discussed in the following section. What is important here is the context, in which the methodology was created: it should enable local governments to choose the location of pilot operation CSSCs.

Among many approaches that were reasonable, we decided to prioritise locations with high unsatisfied demand. The decision was also reflected by the fact that the social indicator (SI) was attributed twice the weight of the other factors in the aggregate index. Without the weighting, there would be a higher correlation of the aggregated index (AI) with economic indicator (EI), thus prioritizing municipalities with a low amount of resources more significantly.

Targeting municipalities with the lowest capacity to address the needs of citizens (unfavorable financial situation, higher unsatisfied demand, and vulnerable population) can also represent a possible limitation of the approach. The CSSCs will be established in areas with underdeveloped infrastructure for provision of social services, which can increase the cost and make the process of selection of suitable human resources difficult.

As the ultimate goal of the project is to replicate the model in all the regions of Slovakia, its main advantage is the ease to adapt for any local government. The methodology works with publicly accessible data that are processed by a simple operation; therefore, it is scalable for the specific needs of the project. As we showed in the results section, aggregation of the pre-selected indicators by their arithmetic means leads to a comparable 
evaluation of the urgency of the need for CSSCs, as building the indicators uses a more complex method of factor analysis.

The simplicity of our approach is at the same time its advantage as well as its limitation. We rely on publicly available data, which are cheap, and it is not time consuming to obtain them. There are, however, several limitations of the data, which affect the computation of each indicator. For the demographic indicator, there are inaccuracies in the objective reporting of migration balance connected to a complicated underlying legal process. For the economic domain, publicly available data were unable to reflect human resources of the municipality; therefore, we had to rely on financial reports. In the social domain, we assume that the data describing the unsatisfied demand are just the tip of the iceberg: the actual need can be much higher, as there are no alternatives for a disabled person.

Finally, for the sake of simplicity, the methodology of selecting the location does not take into account the potential changes in demographic, economic, and social factors in the future, i.e., uncertainty. On the other hand, we consider the development in the given areas stable and, therefore, do not expect significant changes in the measured tendencies.

\section{Conclusions}

The developed methodology of the selection of functional groupings of municipalities, and its application within a specific region, has shown that, despite the aforementioned limitations, this approach to the grouping of municipalities and the establishment of the CSSC is appropriate. It is possible that the methodology may not capture all the elements that indicate appropriateness for siting social and healthcare services, including the integrative care model in rural and remote communities. Future research is planned that will examine other factors indicative of site suitability. Interviews with key informants (i.e., formal and informal caregivers and providers, managers and administrators of social and healthcare services) will show what are the next needs to be considered in implementing care practices with a focus on methodology for the selection of functional groupings of municipalities. The interviews may also uncover information on other determinants of need in the communities, such as the local level of engagement on an integrative care issue, the existence of support networks, political orientation, and the incidence of diseases. Any new information could potentially be added to the siting model to improve decisionmaking for social and healthcare resource allocation. The developed methodology, or its future improved version, is an obvious benefit for municipalities. CSSCs created using the given methodology will help them in providing long-term social and health care for their citizens. The absence of an economic analysis may be another potential limitation to this study. A cost-benefit analysis may also be required to allocate resources, given current restrictions on social and healthcare service spending. We assume that the requirements for the collection and processing of other relevant data within the developed methodology will lead to changes in the statistical survey and data registration. If there is an improvement in records and better data processing, this will certainly lead to better management of financial resources, especially to their more efficient use in the provision of social and health care.

This paper has introduced and described the methods of selection of functional groupings to determine appropriate locations and what needs to be considered in implementing care practices, in this case an integrative care model. Despite long-term care still growing in importance, appropriate care is still not available to all who could benefit from it. Gaps in care delivery have been acknowledged by several countries and social and healthcare providers, which are beginning to address the issue with new frameworks such as the implementation of the integrative care model. Barriers to the delivery of optimal and appropriate care are well known. Residents of rural and remote regions face increased difficulty in accessing these services, including fewer service providers, transportation problems, geographic isolation, and a lack of service availability. Given the seriousness of these problems in the field of long-term social and health care, the aim of the project, in which the methodology of selecting functional groupings of municipalities was developed, 
is to create legislation that would institutionalise the emergence of CSSCs in all regions of Slovakia.

The approach we have chosen, to develop a methodology of selecting the functional groupings of municipalities, can be used as a case study in teaching Management of Territories. Similarly, the use of ArcGIS can be inspiring in teaching Rural Development.

The results of this study are valuable for improving the management and resource allocation for social and healthcare services for the elderly in rural and remote areas, enabling the maximum number of elderly people to benefit from such care. Additionally, the methodology described in this study could be used as a good practice for other Visegrád group countries (The Czech Republic, Poland, and Hungary) because of similarities in connection with economy, culture, and politics.

Author Contributions: Conceptualization, M.H. and A.S.; methodology, A.K., A.V., M.T. and M.H.; software, A.K.; validation, A.V., A.K., A.S. and M.T.; formal analysis, M.H. and A.S.; investigation, A.V. and A.K.; resources, A.V., A.K. and M.H.; writing-original draft preparation, A.V., A.K. and A.S.; writing-review and editing, A.S. and M.T.; supervision, M.T.; project administration, M.H. All authors have read and agreed to the published version of the manuscript.

Funding: This research was founded by the European Commission, DG Employment, Social Affairs and Inclusion, grant number VS/2020/0274.

Institutional Review Board Statement: The study was conducted according to the guidelines of the Declarationof Helsinki, and approved by the Banská Bystrica self-governing region (Slovakia), Approval date 11 March 2021 and University of Matej Bel in Banska Bystrica (Slovakia), Approval date 20 April 2021.

Informed Consent Statement: Not applicable.

Data Availability Statement: The data presented in this study are available and can be obtained via email.

Conflicts of Interest: The authors declare no conflict of interest.

\section{References}

\section{Primary Sources}

Act No. 576/2004 on Health Care and on Services Related to Health Care. Zbierka Zákonov 243: 5238-424.

Act No. 447/2008 Coll. on Financial Benefits to Compensation for Severe Disability and on Amendments to Certain Acts. Zbierka Zákonov 165: 3750-889.

Act No. 448/2008 on Social Services. Zbierka Zákonov 165: 3844-97.

\section{Secondary Sources}

Baxter, Susan, Maxine Johnson, Duncan Chambers, Anthea Sutton, Elizabeth Goyder, and Andrew Booth. 2018. The effects of integrated care: A systematic review of UK and international evidence. BMC Health Service Research 18: 350. [CrossRef] [PubMed]

Cardoso, Teresa, Mónica Duarte Oliveira, Ana Barbosa-Póvoa, and Stefan Nickel. 2015. An Integrated Approach for Planning a Long-Term Care Network with Uncertainty, Strategic Policy and Equity Considerations. European Journal of Operational Research 247: 321-34. [CrossRef]

Chen, Yan-Yan, Honglin Chen, and Priscilla Song. 2020. Promises and Pitfalls of Integrating Home-Based Health Services into Shanghai's Elder-Care System. Ageing and Society 40: 480-500. [CrossRef]

Cinnamon, Jonathan, Nadine Schuurman, and Valorie A. Crooks. 2009. Assessing the Suitability of Host Communities for Secondary Palliative Care Hubs: A Location Analysis Model. Health E Place 15: 822-30. [CrossRef]

Craftman, Åsa Gransjön, Åke Grundberg, and Margareta Westerbotn. 2018. Experiences of Home Care Assistants Providing Social Care to Older People: A Context in Transition. International Journal of Older People Nursing 13: e12207. [CrossRef] [PubMed]

Creswell, John W., and Vicki L. Plano Clark. 2017. Designing and Conducting Mixed Methods Research, 3rd ed. New York: Sage Publication.

Czerska, Iwona, and Malgorzata Skweres-Kuchta. 2021. Integrative Medicine as a New Treatment Model and the Future of Health Care Systems in the World in the Context of Rare Diseases. European Research Studies Journal 24: 800-9. [CrossRef]

de Bruin, Simon R., Jenny Billings, Annerieke Stoop, Manon Lette, Eliva A. Ambugo, Erica Gadsby, Christina Häusler, Konrad Obermann, Gerli-Paat Ahi, Jillian Reynolds, and et al. 2020. Different Contexts, Similar Challenges. SUSTAIN's Experiences with Improving Integrated Care in Europe. International Journal of Integrated Care 20: 17. [CrossRef] [PubMed] 
Freeman, Emily, Martin Knapp, and Ami Somani. 2017. Long-Term Care Organization and Financing. International Encyclopedia of Public Health 7: 469-76. [CrossRef]

Goliáš, Peter, Peter Klátik, and Matej Tunega. 2021. Finančné Zdravie Samosprav za Rok 2020. Available online: http:/ /www.hospod arenieobci.sk/metodika (accessed on 10 June 2021).

Labudová, Viera. 2020. Použitie jednoduchých metód viacrozmerného porovnávania: Analýza zadlženosti domácností. Slovenská Statistika a Demografia 3: 54-74.

Liljas, Anna E. M., Fanny Brattström, Bo Burström, Pär Schön, and Janne Agerholm. 2019. Impact of Integrated Care on Patient-Related Outcomes among Older People-A Systematic Review. International Journal of Integrated Care 19: 6. [CrossRef] [PubMed]

Mauriat, Claire, Matthieu de Stampa, Françoise Simana, Marie Jouannet, Bertrand Garnier, and Bernard Cassou. 2009. Pistes de réflexion à l'intention des professionnels du domicile. Faisant face au refus d'aide/de soins de la part des personnes âgées à domicile. Gérontologie et Société 32: 81. [CrossRef]

Ministry of Social Affairs. 2020. The Report on Social Situation of Inhabitants in the Slovak Republic in 2019. Available online: https:/ / www.employment.gov.sk/files/slovensky/ministerstvo/analyticke-centrum/2020/sprava_o_soc_situacii_obyv atelstva_sr_2019.pdf (accessed on 12 September 2021).

Nicoletti, Giuseppe, Stefano Scarpetta, and Olivier Boylaud. 2000. Summary Indicators of Product Market Regulation with an Extension to Employment Protection Legislation. OECD, ECO Working Paper No. 226. Paris: Economic Co-Operation and Development. [CrossRef]

Owen, Susan Hesse, and Mark S. Daskin. 1998. Strategic Facility Location: A Review. European Journal of Operational Research 111: 423-47. [CrossRef]

Parveen, Huma, and Nayeem Showkat. 2017. An integrative approach to content analysis. In The Content Analysis Guidebook. Edited by Kimberly A. Neuendrof. London: Sage, pp. 36-69.

Porteus, Jeremy. 2011. Living Well at Home Inquiry. All Party Parliamentary Group on Housing and Care for Older People. Available online: https://www.housinglin.org.uk/_assets/Resources/Housing/Support_materials/Other_reports_and_guidance/livin g-well-at-home.pdf (accessed on 2 October 2021).

Shaw, Sara, Rebecca Rosen, and Benedict Rumbold. 2011. What Is Integrated Care? London: The Nuffield Trust, p. 23.

Stallard, Eric. 2017. Long Term Care for Aging Populations. International Encyclopedia of Public Health 7: 447-58. [CrossRef]

Statistical Office of the Slovak Republic. 2020. Datacube Statistics. Available online: http://datacube.statistics.sk/\#!/view/sk/VBD_ DEM/om7022rr/v_om7022rr_00_00_00_sk (accessed on 15 October 2021).

Struijs, Jeroen N., Hanneke W. Drewes, and Viktoria K. Stein. 2015. Beyond integrated care: Challenges on the way towards population health management. International Journal of Integrated Care 15: e043. [CrossRef]

The Organisation for Economic Co-Operation and Development. 2008. Handbook on Constructing Composite Indicators: Methodology and User Guide. Available online: https://www.oecd.org/els/soc/handbookonconstructingcompositeindicatorsmethodologya nduserguide.htm (accessed on 15 May 2021).

The Organisation for Economic Co-Operation and Development. 2011. Public Long-Term Care Financing Arrangements in OECD Countries. Available online: https:/ / outlook.office.com/mail/deeplink?popoutv2=1\&version=20211101003.13 (accessed on 16 May 2021).

Wodchis, Walter P., Toni Ashton, G. Ross Baker, Nicolette Sheridan, Kerry Kuluski, Ann McKillop, Fiona A. Miller, John Parsons, and Timothy Kenealy. 2018. A Research Program on Implementing Intgrated Care for Older Adults with Complex Health Needs (iCOACH): An International Collaboration. International Journal of Integrated Care 18: 11. [CrossRef] [PubMed]

World Health Organisation. 2015. WHO Global Strategy on People-Centred and Integrated Health Services: Interim Report. Available online: https:/ /apps.who.int/iris/handle/10665/155002 (accessed on 20 October 2021).

World Health Organisation. 2016. Integrated Care Models: An Overview. Available online: https://www.euro.who.int/_data/assets /pdf_file/0005/322475/Integrated-care-models-overview.pdf (accessed on 20 October 2021). 